\title{
Kv4.2 knockout mice have hippocampal-dependent learning and memory deficits
}

\author{
Joaquin N. Lugo, ${ }^{1,2,6}$ Amy L. Brewster, ${ }^{1,2}$ Corinne M. Spencer, ${ }^{3}$ and \\ Anne E. Anderson 1,2,4,5,7 \\ ${ }^{1}$ Cain Foundation Laboratories, Jan and Dan Duncan Neurological Research Institute at Texas Children's Hospital, Houston, \\ Texas 77030, USA; ${ }^{2}$ Department of Pediatrics, ${ }^{3}$ Department of Human and Molecular Genetics, ${ }^{4}$ Department of Neurology, \\ and ${ }^{5}$ Department of Neuroscience, Baylor College of Medicine, Houston, Texas 77030, USA
}

\begin{abstract}
Kv4.2 channels contribute to the transient, outward $\mathrm{K}^{+}$current (A-type current) in hippocampal dendrites, and modulation of this current substantially alters dendritic excitability. Using Kv4.2 knockout (KO) mice, we examined the role of Kv4.2 in hippocampal-dependent learning and memory. We found that Kv4.2 KO mice showed a deficit in the learning phase of the Morris water maze (MWM) and significant impairment in the probe trial compared with wild type (WT). $\mathrm{Kv} 4.2 \mathrm{KO}$ mice also demonstrated a specific deficit in contextual learning in the fear-conditioning test, without impairment in the conditioned stimulus or new context condition. Kv4.2 KO mice had normal activity, anxiety levels, and prepulse inhibition compared with WT mice. A compensatory increase in tonic inhibition has been previously described in hippocampal slice recordings from $\mathrm{Kv} 4.2 \mathrm{KO}$ mice. In an attempt to decipher whether increased tonic inhibition contributed to the learning and memory deficits in Kv4.2 KO mice, we administered picrotoxin to block $\mathrm{GABA}_{\mathrm{A}}$ receptors (GABA $\mathrm{G}$ ), and thereby tonic inhibition. This manipulation had no effect on behavior in the WT or KO mice. Furthermore, total protein levels of the $\alpha 5$ or $\delta \mathrm{GABA}_{\mathrm{A}}$ R subunits, which contribute to tonic inhibition, were unchanged in hippocampus. Overall, our findings add to the growing body of evidence, suggesting an important role for Kv4.2 channels in hippocampal-dependent learning and memory.
\end{abstract}

Potassium $\left(\mathrm{K}^{+}\right)$channels within hippocampal dendrites are critical regulators of post-synaptic excitability and thereby contribute to the modulation of synaptic plasticity (Yuan and Chen 2006). In particular, the transient, rapidly activating $\mathrm{K}^{+}$current (A-type current) modulates neuronal excitability by attenuating action potential initiation and back-propagating action potentials (B-APs), which reduce excitatory synaptic events (Hoffman et al. 1997; Martina et al. 1998; Johnston et al. 2000; Cai et al. 2004). The primary mediator of the A-type current in the somatodendritic regions of hippocampal pyramidal cells are the Kv4.X-subunits, and genetic deletion of Kv4.2 channels nearly eliminates the A-type current in CA1 pyramidal cell dendrites (Chen et al. 2006). The localization and function of Kv4.2 channels support a role for these channels in modulating synaptic activity in the hippocampus and influencing hippocampal-dependent tasks.

$\mathrm{Kv} 4.2$ channel proteins localize to the somatodendritic regions of hippocampal principal neurons (Baldwin et al. 1991; Sheng et al. 1992; Maletic-Savatic et al. 1995; Martina et al. 1998; Serodio and Rudy 1998), and their highest expression is found in area CA1 pyramidal cell dendrites (Rhodes et al. 2004). These channel proteins localize to dendritic spines, where their activity can be modulated through auxiliary subunits and through a number of kinases. For example, activation of PKA, PKC, and ERK can down-regulate the activity and surface expression of Kv 4.2 channels, which can then increase excitability within distal dendrites of CA1 neurons (for review, see Birnbaum et al. 2004).

\footnotetext{
6Present address: Baylor University, Department of Psychology and Neuroscience, Waco, TX 76706, USA.

${ }^{7}$ Corresponding author.

E-mail annea@bcm.edu.

Article is online at http://www.learnmem.org/cgi/doi/10.1101/Im.023614.111.
}

Furthermore, alterations in the functional levels of Kv4.2 channels can directly modulate synaptic remodeling through reorganization of NMDA-type glutamate receptor subunits (Jung et al. 2008). These changes then lead to alterations in synaptic plasticity and memory (for review, see Malenka and Bear 2004). The activity level of Kv4.2 channels influences dendritic $\mathrm{Ca}^{2+}$ influx during action potential back-propagation (Hoffman et al. 1997). An increase in intracellular $\mathrm{Ca}^{2+}$ levels is necessary for long-term potentiation (LTP). Taken together these observations suggest that Kv4.2 channels are critical determinants of hippocampal plasticity, and thereby hippocampal-dependent learning tasks. In this study Kv4.2 knockout (KO) and littermate wild-type (WT) control mice were subjected to a battery of behavioral assessments to test the hypothesis that $\mathrm{Kv} 4.2$ channels are required for hippocampal-dependent learning and memory.

\section{Results}

Spatial learning and memory

In order to assess hippocampal-dependent learning and memory in the Kv4.2 KO mice, we first performed the Morris water maze (MWM) test. In the MWM test, the animals learn to find a hidden platform over blocks of training using visual cues in the testing room. A main effect of genotype was observed in which $\mathrm{KO}$ mice showed significant impairment in locating the hidden platform across the eight blocks of testing $\left(F_{(1,29)}=11.04, P<0.01\right)$. There was also a significant group by block interaction $\left(F_{(7,203)}=\right.$ 3.05, $P<0.01)$ (Fig. 1A) and a main effect of time $\left(F_{(7,203)}=\right.$ $18.21, P<0.001)$. Both WT and KO mice showed significant improvement in finding the platform across the blocks [WT: $\left(F_{(7,98)}=14.446, P<0.001\right)$ and KO: $\left.\left(F_{(7,105)}=4.50, P<0.001\right)\right]$. 


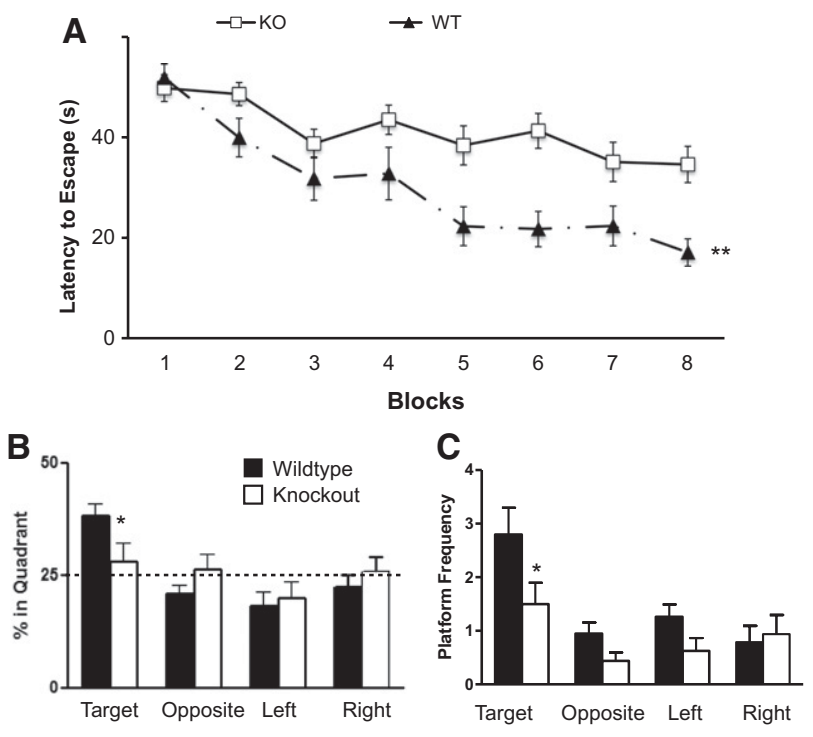

Figure 1. Kv4.2 knockout (KO) mice showed impairment in spatial learning and memory. Wild-type (WT) and Kv4.2 KO mice were examined for differences in acquisition and retention of spatial memory in the Morris water maze. The mice were trained over eight blocks to find the hidden platform. (A) Kv4.2 KO mice showed impairment in the ability to learn to find the hidden platform. After eight blocks of learning were completed, the animals were tested for spatial memory retention by the probe trial. The Kv4.2 KO mice spent less time in the target quadrant compared with the WT mice $(B)$ and had decreased crossings in the region that previously housed the hidden platform (target quadrant) (C). Data are shown as mean \pm standard error of the mean. $\left(^{*}\right) P<0.05 ;\left(^{* *}\right) P<0.01 ; n=15$ (WT); $n=16$ (KO).

Separate $t$-tests were conducted on each block, and significant differences between WT and KO mice were found on blocks 5-8 $(P<$ $0.05)$. KO mice also had a longer path length to reach the hidden platform across training. There was a main effect of group for path length $\left(F_{(1,29)}=5.09, P<0.05\right)$ and a group by block interaction $\left(F_{(7,203)}=3.10, P<0.01\right)$. These results indicated that both groups showed significant improvement across the blocks, but the Kv4.2 $\mathrm{KO}$ mice did not learn to find the hidden platform as well as the WT mice.

To confirm that the mice used a spatial search strategy to locate the hidden platform, the animals were then tested in the probe trial. The probe trial consists of removing the hidden platform and allowing the animal to explore the maze for $60 \mathrm{sec}$. If the animal had learned to find the hidden platform using spatial cues then they should spend more time in the quadrant that previously had contained the hidden platform (target quadrant) and cross over the specific area corresponding to the previous location of the hidden platform (target zone). WT mice showed a difference in the percentage of time they spent in the four quadrants during the probe trial $\left(F_{(3,42)}=9.64, P<0.001\right)$. The WT mice spent more time in the target quadrant compared with the other quadrants (all post hoc tests were significant, $P<0.05$ ). However, the $\mathrm{Kv} 4.2 \mathrm{KO}$ mice spent equal time in all quadrants $\left(F_{(3,45)}=\right.$ $0.68, P=0.57)$, indicating lack of a spatially selective search strategy. WT mice also spent more time in the target quadrant compared with the Kv4.2 KO mice $\left(t_{(1,29)}=2.12, P<0.05\right)$ (Fig. 1B). Platform crossings are used as an indicator of the accuracy of the spatial search. A two-way repeated ANOVA revealed a significant difference $\left(F_{(1,29)}=5.97, P<0.05\right)$ in the number of times the mice crossed the previous location (zone) of the hidden platform between the two genotypes. A separate analysis showed that the WT mice crossed the location where the hidden platform was pre- viously placed (target zone) more frequently than the $\mathrm{KO}$ mice $\left(t_{(1,29)}=2.14, P<0.05\right)$ (Fig. 1C). These results indicate that the Kv4.2 KO mice have spatial learning deficits in the MWM.

To ensure that the spatial learning impairment was not due to the inability of the Kv4.2 KO mice to see visible cues, $1 \mathrm{~d}$ after the probe trial a visible platform was placed in the MWM and the latency to find that the visible platform was recorded. The WT and KO mice showed no difference $\left(t_{(1,29)}=0.38, P=0.54\right)$ in the time to reach the visible platform $(12.31 \pm 2.17 \mathrm{sec}$ and $14.74 \pm 2.11$ $\mathrm{sec}$, respectively). We also examined the latency to find a visible platform in naive (never before tested in the MWM) WT and KO mice. The naive WT and KO mice had no difference $\left(t_{(1,18)}=\right.$ 0.83, $P=0.37$ ) in the time to reach the hidden platform $(17.56 \pm 3.2$ and $17.04 \pm 2.23$, respectively). The lack of differences in the time to reach the visible platform implies that the $\mathrm{Kv} 4.2 \mathrm{KO}$ mice can see the visible platform, so the genetic deletion does not appear to affect their ability to see, and they do not have motor impairments that significantly interfere with swimming or climbing onto the platform.

\section{Pavlovian fear conditioning}

To examine whether the Kv4.2 KO mice have a specific deficit in spatial learning or a more pervasive hippocampal learning and memory deficit, contextual fear conditioning was examined. The mice were first trained to associate the context in which they were trained with the shock, and associate a conditioned stimulus (CS:tone) with the shock. During the training phase the Kv4.2 KO mice showed a similar level of percent freezing time compared with WT mice during the first 2 min in the conditioning chamber $\left(t_{(1,31)}=0.74, P>0.05\right.$ : KO: $16.5 \pm 5.2$ vs. WT: $\left.22.3 \pm 5.6\right)$ and when the conditioned stimulus (CS) was presented for $30 \mathrm{sec}$ $\left(t_{(1,31)}=0.46, P>0.05: \mathrm{KO}: 36.2 \pm 8.0\right.$ vs. WT: $\left.41.0 \pm 6.8\right)$. All WT and $\mathrm{KO}$ mice displayed a reaction to the shock stimulus (running, jumping, or vocalizing). On the second day, the animals were first tested for the ability to associate the context (chamber) with the shock. There was a significant difference in contextual learning in the fear-conditioning test $\left(t_{(1,31)}=3.43, P<0.001\right)$, with decrease in freezing in the context condition compared with WT mice (Fig. 2A). The second part of the test examined whether the animals associated a CS (tone) to the shock. There was no difference in freezing to the CS $\left(t_{(1,31)}=0.29, P>0.05\right.$ : WT: $60.1 \pm 7.6$; KO: $63.2 \pm 7.2$ ) (Fig. $2 \mathrm{~B}$ ) and no difference in freezing
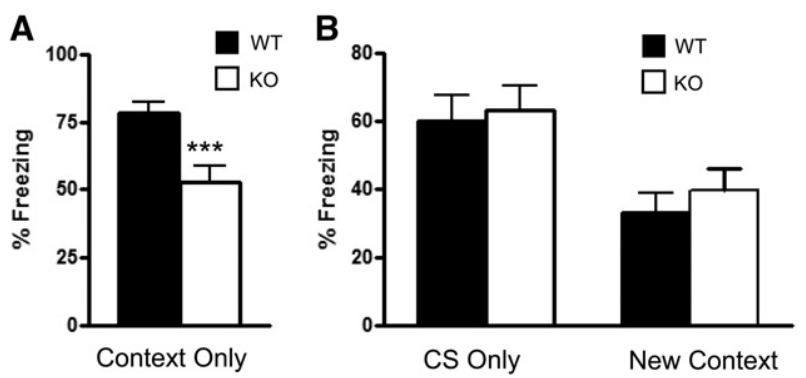

Figure 2. Kv4.2 knockout mice showed impairment in contextual learning in the fear-conditioning paradigm. Kv4.2 KO mice and wild-type (WT) mice were examined for differences in learning and memory through fear conditioning. ( $A$ ) The Kv4.2 KO mice had decreased freezing in the contextual learning condition compared with the WT mice. This change was specific to contextual learning, since they did not show an alteration in freezing for the CS-only condition or in the new context condition (B). These data suggest that Kv4.2 mice have a specific impairment in hippocampal-dependent memory without a change in amygdaladependent memory. Data are shown as mean \pm standard error of the mean. (***) $P<0.001 ; n=18$ (WT), $n=15$ (KO). 
in a new context $\left(t_{(1,31)}=0.90, P>0.05\right.$ : WT: $33.1 \pm 5.7 ; \mathrm{KO}$ : $39.6 \pm 6.3$ ) (Fig. 2B), indicating that the learning deficit was specific to the contextual condition. Thus, the results from the MWM and contextual fear conditioning behavioral tests suggest that the Kv4.2 KO mice have hippocampal-dependent learning and memory deficits. Together, these results provide further support for a critical role for Kv4.2 in hippocampal-dependent learning and memory.

\section{Locomotor activity}

To examine whether Kv4.2 KO mice have abnormal motor function, which could influence swim mobility, we examined the mice in an open field test. No statistically significant differences between the WT $(n=19)$ and KO $(n=15)$ groups were found in horizontal activity $\left(t_{(1,31)}=0.51, P=0.61\right)$, vertical activity $\left(t_{(1,31)}=0.32, P=0.74\right)$, center activity $\left(t_{(1,31)}=0.24, P=0.81\right)$, center/total distance ratio $\left(t_{(1,31)}=0.99, P=0.33\right)$ (Table 1$)$. In addition there was no difference in weight between the two genotypes $\left(t_{(1,31)}=0.85, P=0.40\right)$ (Table 1$)$. These results indicate that Kv4.2 knockout mice do not have deficits in gross locomotor activity compared with littermate WT mice. However, there was a statistically significant decrease in the number of fecal boli produced from Kv4.2 $\mathrm{KO}\left(t_{(1,31)}=2.12, P<0.05\right)$ compared with WT mice (Table 1). One explanation for the decrease in number of fecal boli is that the Kv4.2 KO mice are less anxious than WT mice, although the lack of difference in the center distance/ total distance ratio does not support a difference in anxiety-like behavior.

\section{Elevated-plus maze}

Since one interpretation of the decreased number of fecal boli is that the difference may be due to alterations in anxiety in the $\mathrm{Kv} 4.2 \mathrm{KO}$ mice, we tested them in the elevated-plus test, which more selectively examines anxiety-like behavior. The test involves exploration of a plus-shaped maze that consists of two open and two closed arms, where decreased time in the open arms is considered an indicator of elevated anxiety. There were no differences between $\mathrm{KO}$ and $\mathrm{WT}$ mice in the amount of time spent in the closed $\left(t_{(1,31)}=1.34, P=0.19\right)$ and open arms of the maze $\left(t_{(1,31)}=0.46, P=0.64\right)$; (Fig. 3, A and B, respectively). There were no differences in the number of entries into the closed (WT: $22.23 \pm 2.43, n=19$; KO: $28.36 \pm 2.37, n=14$ ) or in open (WT: $8.60 \pm 2.83, n=19$; KO: $8.80 \pm 1.62, n=14$ ) arms. These findings do not support an alteration in anxiety in the Kv4.2 KO mice, as their performance was not significantly different from littermate WT mice. The difference in the number of fecal boli may be due to the effects of $\mathrm{Kv} 4.2 \mathrm{KO}$ in the gastrointestinal tract, since these channels are expressed in smooth muscle of this region (Koh et al. 1999). It did not appear that the animals were eating more, which might also account for increased fecal boli, since their weight was similar to that of the WT mice (Table 1).

Table 1. Open field activity

\begin{tabular}{lcccccc}
\hline Group & $\begin{array}{c}\text { Total activity } \\
\text { crossings }\end{array}$ & $\begin{array}{c}\text { Vertical } \\
\text { activity } \\
\text { crossings }\end{array}$ & $\begin{array}{c}\text { Center } \\
\text { activity } \\
\text { crossings }\end{array}$ & $\begin{array}{c}\text { Center/ } \\
\text { total ratio }\end{array}$ & Fecal boli & Weight (g) \\
\hline Wild type, & 1964 & 4.74 & 40.53 & \pm 0.024 & 7.56 & 27.14 \\
$\quad \begin{array}{l}n=19 \\
\text { Kv4.2 }\end{array}$ & \pm 201.7 & \pm 1.81 & \pm 9.56 & \pm 0.004 & \pm 0.76 & \pm 0.037 \\
$\quad$ knockout, & \pm 232 & 5.53 & 44.37 & 0.017 & 5.13 & 27.66 \\
$n=15$ & & \pm 1.49 & \pm 11.66 & \pm 0.005 & $\pm 0.85^{\text {a }}$ & \pm 0.47 \\
\hline
\end{tabular}

astatistically significant at $P<0.05$.
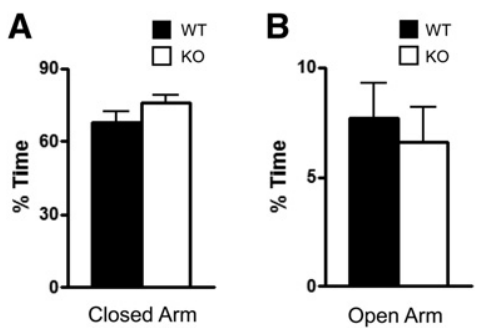

Figure 3. Kv4.2 knockout mice did not show a change in anxiety compared with wild-type mice. WT and Kv4.2 KO mice were tested for differences in anxiety using the elevated-plus maze for $10 \mathrm{~min}$. The amount of time spent in the closed arms $(A)$ and open arms $(B)$ of the elevated-plus test were not significantly different between WT and Kv4.2 KO mice. Data are shown as mean \pm standard error of the mean. $P>0.05 ; n=19(\mathrm{WT})$, $n=14(\mathrm{KO})$.

\section{Sensorimotor testing}

A necessary condition for the prepulse inhibition test and the tone portion of the fear-conditioning test is for the animal to have normal hearing. To examine whether the Kv4.2 KO mice have normal hearing and sensorimotor control, which could influence cued fear conditioning, the mice were examined in the prepulse inhibition test. The acoustic stimulus of $120 \mathrm{~dB}$ was used, and the Kv4.2 KO mice showed the same response to a loud audio stimulus compared with the WT mice $\left(t_{(1,31)}=0.16\right.$, $P>0.05$ ) (Fig. 4A). The mice were then subjected to the acoustic startle response using pseudorandom prepulse levels of different intensities and did not show a statistically significant difference compared with WT mice across the three stimuli using a two-way repeated-measures ANOVA for group: $\left(F_{(1,36)}=1.3, P=0.26\right)$ (Fig. $4 \mathrm{~B})$. There was a main effect where the animal responded more as the intensity of the prepulse sound stimulus was increased $\left(F_{(2,72)}=47.61, P<0.001\right)$, but no group interaction over the three stimuli $\left(F_{(2,72)}=0.37, P=0.69\right)$. These results suggest that the Kv4.2 KO mice show normal sensorimotor gating.

\section{Western blotting for $\mathrm{GABA}_{\mathrm{A}}$ receptor subunit proteins}

Andrásfalvy et al. (2008) previously reported an increase in the tonic GABA current in area CA1 from $\mathrm{Kv} 4.2 \mathrm{KO}$ mice. In order to examine whether the increase in tonic GABA current was due to alterations in $\mathrm{GABA}_{\mathrm{A}}$ receptor $\left(\mathrm{GABA}_{\mathrm{A}} \mathrm{R}\right)$ subunit protein, we investigated two $\mathrm{GABA}_{\mathrm{A}} \mathrm{R}$ subunits: $\alpha 5$ and $\delta$ that have been implicated as the primary mediators of the tonic GABA current in hippocampus (Glykys et al. 2008). Using Western blotting, we found no change in the protein levels of the $\alpha 5 \mathrm{GABA}_{\mathrm{A}} \mathrm{R}$ subunit in total hippocampal homogenates between WT and Kv4.2 KO mice $\left(t_{(1,10)}=0.02, P=0.98, n=7,5\right.$, respectively) (Fig. 5A). We also found no change in the protein levels of the $\delta G_{A B A} R$ subunit in total hippocampal homogenates for WT and Kv4.2 KO mice $\left(t_{(1,11)}=0.20, P=0.85, n=7,6\right.$, respectively) (Fig. 5B). Similar results were found in synaptosomal preparations from hippocampus for the $\alpha 5 \mathrm{GABA}_{\mathrm{A}} \mathrm{R}$ for WT and Kv4.2 KO mice $\left(t_{(1,10)}=0.29, P=0.78\right.$ : WT: $100 \pm 16.14, \quad n=7 ; \quad \mathrm{KO}: 105 \pm 7.43$, $n=6)$ and for $\delta \mathrm{GABA}_{\mathrm{A}} \mathrm{R}$ for $\mathrm{WT}$ and Kv4.2 KO mice $\left(t_{(1,11)}=1.67, P=0.13\right.$ : WT: $100 \pm 33.57, n=6$; KO: $155 \pm$ $11.65, n=5)$. Therefore, the hippocampal-dependent learning deficits observed in the Kv4.2 KO mice did not appear to be due to compensatory changes in $\alpha 5$ or $\delta \mathrm{GABA}_{\mathrm{A}} \mathrm{R}$ subunits 

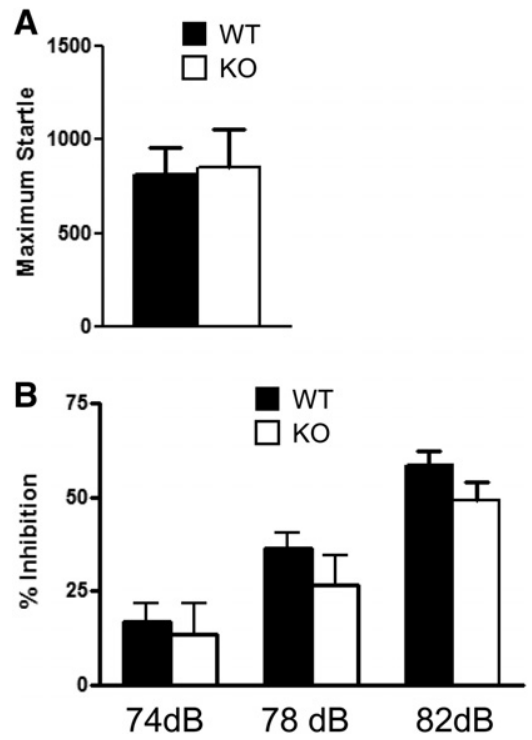

Figure 4. Kv4.2 knockout mice showed normal acoustic startle and sensorimotor gating. The Kv4.2 KO and wild-type mice were examined for differences in acoustic startle and sensorimotor gating through prepulse inhibition of acoustic startle. (A) The maximum startle response amplitude to the acoustic startle stimulus was not different between the groups. (B) The Kv4.2 KO mice did not show any alterations in acoustic stimulus to varying levels of startle. Data are shown as mean \pm standard error of the mean. $P>0.05 ; n=24(\mathrm{WT}), n=15(\mathrm{KO})$.

in the hippocampus. However, a small change in the protein levels of these receptors in area CA1 could be missed in assays using the whole hippocampus. Furthermore, post-translational modifications could change receptor function without altering total receptor protein levels.

\section{Pharmacological inhibition of $\mathrm{GABA}_{\mathrm{A}}$ neurotransmission using picrotoxin}

To further explore the possible contribution of increased tonic inhibition in the hippocampal-dependent learning and memory deficits in $\mathrm{Kv} 4.2 \mathrm{KO}$ mice, we administered picrotoxin $(0.01 \mathrm{mg} /$ $\mathrm{kg}$ I.P.), a noncompetitive $\mathrm{GABA}_{\mathrm{A}} \mathrm{R}$ antagonist to groups of $\mathrm{KO}$ and WT mice and compared the performance of these groups with those treated with vehicle in the MWM test. The $\mathrm{GABA}_{\mathrm{A}} \mathrm{R}$ antagonist had no effect on behavior in the WT mice, nor did it rescue the spatial learning and memory deficits in the $\mathrm{Kv} 4.2 \mathrm{KO}$ mice during the training phase (Fig. 5C) or during the probe trial in the Kv4.2 KO mice (Fig. 5D) of the MWM test. There was no main effect of group $\left(F_{(3,27)}=0.92, P=0.443\right)$, but there was a significant contrast interaction between group over the blocks of learning $\left(F_{(3,27)}=3.93, P=0.02\right)$. Separate one-way ANOVAs revealed significant differences on block $7\left(F_{(3,27)}=5.10, P<0.01\right)$ and on block $8\left(F_{(3,27)}=3.12, P<0.05\right)$ in the Kv4.2 $\mathrm{KO}$ mice treated with saline or picrotoxin compared with the $\mathrm{Kv} 4.2$ wildtype mice treated with saline or picrotoxin (Fig. 5C). Testing in the probe trial revealed that the picrotoxin treatment did not rescue memory deficits in the Kv4.2 KO mice. The saline and picrotoxin-treated $\mathrm{KO}$ mice did not show a preference to the target quadrant (Fig. 5D). In addition, picrotoxin treatment did not affect memory in the probe trial in WT mice. The WT-saline group showed a significant preference for the target quadrant $\left(F_{(3,27)}=\right.$ 5.39, $P<0.01)$ as did the WT-picrotoxin-treated group $\left(F_{(3,27)}=\right.$ $3.83, P<0.05)$.

Thus, based on a lack of effect of picrotoxin in either the WT or KO groups, these studies are inconclusive with regard to a con- tribution of altered inhibitory tone in the behavioral phenotype seen in these mice. We used a subconvulsant dose of picrotoxin for these studies, and perhaps this dose was insufficient to block $\mathrm{GABA}_{\mathrm{A}} \mathrm{Rs}$ and tonic inhibition. In addition, the possibility exists that even in the presence of $\mathrm{GABA}_{\mathrm{A}} \mathrm{R}$ blockade, hippocampaldependent learning and memory as assessed by the MWM test may be unaffected. Indeed, the role of tonic inhibition in hippocampal-dependent learning and memory has not been extensively characterized.

\section{Discussion}

The studies presented here reveal that $\mathrm{Kv} 4.2 \mathrm{KO}$ mice have significant deficits in hippocampal-dependent learning and memory tasks. In contrast, these mice show normal learning in the amygdala-dependent portion of the fear conditioning test and do not demonstrate alterations in locomotion, anxiety, startle
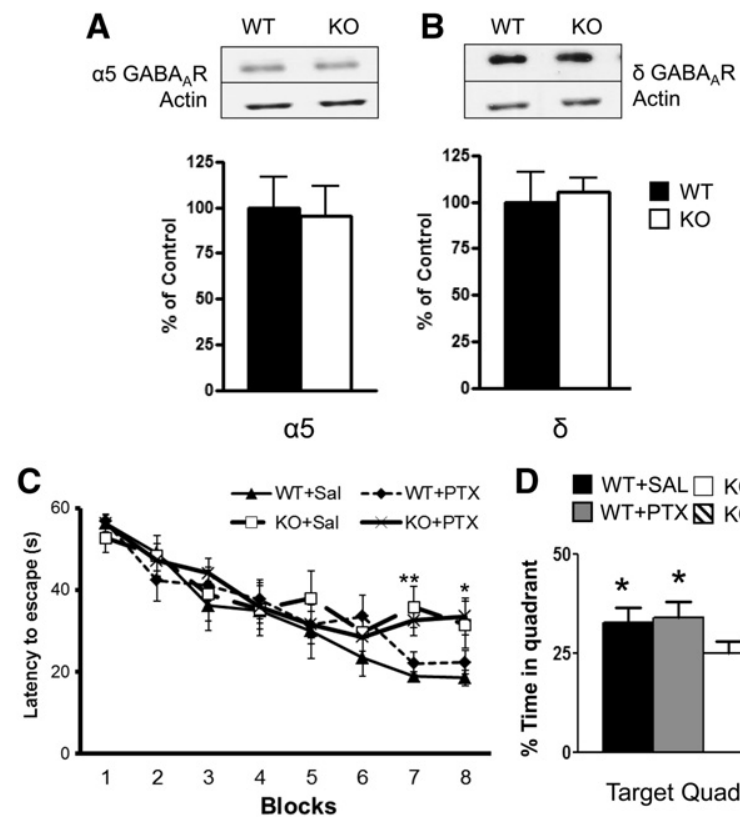

D WTTSAL $\square$ KO+SAL $\square W T+P T X \mathbb{Q}$ KO+PTX

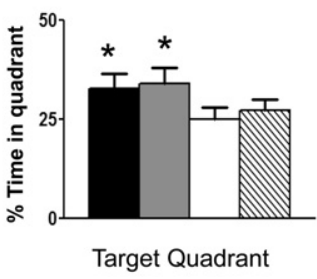

Figure 5. $\alpha 5$ and $\delta G A B A_{A}$ receptor subunit levels were unchanged, and pharmacological suppression of tonic inhibition does not reverse the spatial learning and memory deficits in Kv4.2 knockout mice. The protein levels of $\alpha 5$ or $\delta G A B A_{A} R$ subunits were assessed in the $K O$ and wild-type mouse hippocampus. The hippocampus was removed from $\mathrm{Kv} 4.2 \mathrm{KO}$ mice and WT mice and total homogenates and crude synaptosomes were prepared. $(A, B$, top) Representative blots from these samples were probed with antibodies against total $\alpha 5$ and $\delta G A B A_{A} R$. The protein levels were densitized for $\alpha 5 G_{A B A_{A} R}$ subunit and $\delta G_{A B A_{A} R}$ subunit. There was no significant change between the WT and Kv4.2 KO mice. $P>0.05 ; n=7$ (WT). WT and Kv4.2 KO mice were injected (intraperitoneally) with saline or $0.01 \mathrm{mg} / \mathrm{kg}$ of picrotoxin and then tested in the Morris water maze (MWM) for differences in acquisition and retention of spatial memory. The mice were injected for $3 \mathrm{~d}$ prior to training and throughout testing. (C) Kv4.2 KO mice show impairment in the ability to learn to find the hidden platform. However, administration of picrotoxin did not improve performance in $\mathrm{Kv} 4.2 \mathrm{KO}$ mice and had no effect on behavior in the WT mice. After the blocks of learning were completed, the animals were tested for spatial memory retention using the probe trial. The Kv4.2 KO mice spent less time in the target quadrant compared with the WT mice $(D)$, but the picrotoxin-treated animals did not show any improvement compared with the saline-treated WT mice. Overall, the noncompetitive $G A B A_{A} R$ antagonist, picrotoxin, had no effect on the behavior of the WT or KO mice in the MWM. Data are shown as mean \pm standard error of the mean. $\left({ }^{*}\right) P<0.05 ;\left({ }^{* *}\right) P<0.01 ; n=7$ (WT + sal), $n=8$ (WT + picrotoxin), $n=6(\mathrm{KO}+$ saline $), n=9(\mathrm{KO}+$ picrotoxin). 
response, or sensorimotor gating. Thus, these findings provide further support for a critical role of Kv4.2 channels in hippocampal-dependent learning and memory.

We initially hypothesized that $\mathrm{Kv} 4.2 \mathrm{KO}$ mice would have enhanced hippocampal-dependent learning and memory, since this genetic deletion has been shown to nearly eliminate the A-type current in the dendrites of CA1 pyramidal cells, lead to a larger B-AP, more calcium influx, and lowers the threshold to induce LTP (Chen et al. 2006). The lower induction threshold to LTP in the Kv4.2 KO mice might lead one to hypothesize a steeper learning curve, but, overall, the same learning capacity as WT animals. Unfortunately, the relationship between enhanced synaptic plasticity due to genetic manipulations and the influence on learning and memory is one that is complex and that does not always correlate (Sanes and Lichtman 1999). For example, there are studies showing that diminished LTP does not lead to a deficit in spatial learning, and that mice with enhanced LTP have impaired spatial memory performance (Migaud et al. 1998; Zamanillo et al. 1999).

Furthermore, our results corroborate a recent study demonstrating that Kv4.2 KO mice have spatial learning and memory deficits (Lockridge and Yuan 2010). This study reported that $\mathrm{Kv} 4.2 \mathrm{KO}$ mice show a selective decrease in the latency to find the hidden platform in the MWM on day 3 of training. The $\mathrm{Kv} 4.2 \mathrm{KO}$ mice were able to learn to find the new location of the hidden platform in reversal learning in the MWM. They also found that Kv4.2 KO mice used fewer spatial strategies than WT mice during the early learning trials. Our studies expand those of Lockridge and Yuan 2010 by examining performance of the Kv4.2 $\mathrm{KO}$ animals in additional behavioral tests to determine whether these animals have alterations in anxiety and locomotion. We also conducted fear-conditioning assessments and determined that $\mathrm{Kv} 4.2 \mathrm{KO}$ mice have context-dependent learning deficits and not global learning deficits. However, even though we found that Kv4.2 KO mice had deficits in their ability to learn the MWM task, they did not show differences in their ability for contextual learning in the training phase of the fear-conditioning test. Future experiments could examine whether Kv 4.2 mice show deficits in trace fear conditioning, which is believed to be a sensitive measure of hippocampal dysfunction (Wiltgen et al. 2005). Additional trials of tone-shock pairings could be used to examine deficits in the acquisition of contextual learning, and we could examine whether the contextual deficits occur within $1 \mathrm{~h}$ after conditioned fear training.

It has been previously reported that $\mathrm{Kv} 4.2 \mathrm{KO}$ mice have decreased KChIP1-3 auxiliary subunit protein levels (Chen et al. 2006; Menegola and Trimmer 2006), which are critical regulators of Kv4.2 activity and expression (Birnbaum et al. 2004). While the role of KChIP1 and KChIP2 in behavior has not been evaluated, KChIP $3 \mathrm{KO}$ mice have recently been reported to have enhanced memory in contextual fear conditioning (Alexander et al. 2009). However, KChIP3 KO mice do not have altered Kv4.2 protein levels in the hippocampus. At this point, it is unclear whether alterations in KChIP levels contribute to the behavioral phenotype in the Kv4.2 KO mice.

An increase in magnitude of the tonic GABA current and an increase in the amplitude of mIPSCs in CA1 pyramidal cells in hippocampal slices from $\mathrm{Kv} 4.2 \mathrm{KO}$ mice has been reported (Andrásfalvy et al. 2008). These investigators proposed that the increase in the tonic GABA current in area CA1 from Kv4.2 KO mice might be a homeostatic response to increased membrane excitability due to the loss of the A-type current in the dendrites of CA1 pyramidal cells. We hypothesized that this change may contribute to the behavioral phenotype in the Kv4.2 KO mice. The primary mediators of the tonic GABA current in hippocampal neurons are $\alpha 5$ and $\delta \mathrm{GABA}_{\mathrm{A}} \mathrm{R}$ subunits (Glykys et al. 2008). In further support of this possibility, it has been reported that $\alpha 5$ $\mathrm{GABA}_{\mathrm{A}} \mathrm{R}$ subunit knockout mice have improved performance in MWM, without alterations in amygdala-dependent learning and memory (Collinson et al. 2002). In addition, the $\delta G_{A B A_{A} R}$ subunit knockout mice also show enhanced trace fear conditioning (Wiltgen et al. 2005). Therefore, the absence of Kv4.2 channels with an associated loss of the dendritic A-type current in hippocampal area CA1 along with increased tonic inhibition from alterations in $\mathrm{GABA}_{\mathrm{A}}$ Rs could affect learning and memory (Caraiscos et al. 2004; Glykys et al. 2008). To indirectly assess the possibility of increased $\mathrm{GABA}_{\mathrm{A}}$ inhibitory neurotransmission in the $\mathrm{Kv} 4.2 \mathrm{KO}$ mice, we evaluated the protein levels of $\alpha 5$ and $\delta G A B A_{A} R$ subunits. We found no difference in $\alpha 5$ and $\delta \mathrm{GABA}_{\mathrm{A}} \mathrm{R}$ subunit protein levels between the WT and Kv4.2 KO mice in hippocampal homogenate or synaptosomal preparations. We also found that pharmacological antagonism of $\mathrm{GABA}_{\mathrm{A}} \mathrm{Rs}$ with picrotoxin, which is expected to suppress tonic inhibition, did not rescue the learning and memory deficits in Kv4.2 KO mice. However, this pharmacological manipulation had no effect in the WT mice either. Thus, we are unable to draw any conclusions from this aspect of the study. Higher doses of picrotoxin are known to evoke seizures, which would confound the studies.

Based on our data, the behavioral phenotype in Kv4.2 KO mice is specific to the hippocampus, which has the highest expression level of Kv4.2 channels (Rhodes et al. 2004). While the mice have a global knockout of Kv4.2, the KO mice did not show any other behavioral abnormalities, and their general ability to learn was not disrupted, as shown through the conditioned stimulusonly portion of fear conditioning. Kv 4.2 channels have a regulatory role in a number of processes in hippocampus, such as suppressing plateau potentials from exceeding beyond dendritic branch points (Cai et al. 2004). The internalization of Kv4.2 channels significantly affects plasticity by controlling synaptic integration in the spines of hippocampal neurons (Kim et al. 2007). The absence of Kv 4.2 channels widens the temporal window to induce LTP and increases the threshold to induce LTD (Chen et al. 2006). Thus, the absence of this channel may affect the ability of dendrites to appropriately integrate incoming signals, which could then affect the ability of the animal to acquire new information. It is possible that the activity-dependent changes in Kv4.2 channel trafficking, expression, and post-translational modifications may be a necessary step for hippocampal-dependent learning.

Alterations in the modulation and expression of Kv4.2 channels have been associated with neurological disorders. A truncation mutation in then KCND2 gene encoding Kv4.2 channels has been associated with temporal lobe epilepsy (Singh et al. 2006). Furthermore, Kv4.2 expression and phosphorylation is altered in animal models of temporal lobe epilepsy in both the acute (Lugo et al. 2008) and chronic (Bernard et al. 2004) phases. While Kv4.2 KO mice do not have unprovoked seizures or epilepsy, they have an increased susceptibility to chemoconvulsantinduced seizures (Barnwell et al. 2009). These previous studies suggest that a reduction in the levels of functional Kv4.2 channels is involved in the development of epilepsy. Furthermore, it is possible that alterations in ion channels such as $\mathrm{Kv} 4.2$ contribute to cognitive deficits associated with epilepsy.

\section{Materials and Methods}

\section{Animals}

Mice were housed at the Baylor College of Medicine Transgenic Mouse Facility Center at a temperature of $22^{\circ} \mathrm{C}$, with 14-h light and 10-h dark (20:00-6:00 h) diurnal cycle and had free access to food and water. All procedures were approved by the Institutional Animal Care and Use Committee of Baylor College of Medicine, which follows the "Policy on Humane Care and 
Use of Laboratory Animals" and NIH's "Guide for the Care and Use of Laboratory Animals."

The Kv4.2 KO mice used in this study were generated in a 129S6/SvEv background (Guo et al. 2005). The KO mice were backcrossed with WT $129 \mathrm{~S} 6 / \mathrm{SvEv}$ to produce (F10 or greater) littermates that were used in these studies. The Kv4.2 KO and WT animals were from the offspring of heterozygote parents. The mice began behavioral testing on approximately post-natal day 90. Genotyping of littermates was performed by PCR using Kv4.2-specific primers as previously described (Barnwell et al. 2009).

\section{Behavioral assessments}

\section{Locomotor activity and motor skills}

Locomotor activity was evaluated as previously described (Paylor et al. 2006). First, the animals were tested in the open-field activity test. The mice were weighed and allowed to acclimatize to the testing room for $30 \mathrm{~min}$. They were then placed into the center of a clear Plexiglas $(40 \times 40 \times 30 \mathrm{~cm})$ open-field arena and allowed to explore for $30 \mathrm{~min}$. The lighting inside the test chamber was $\sim 100$ lux, and a white noise generator produced $\sim 55 \mathrm{~dB}$ inside the test arena. Activity in the open field was collected by a computer-operated optical animal activity system (Versamax by AccuScan Instruments, Inc.). Total distance (locomotor activity), vertical activity (rearing measured by number of photobeam interruptions), and center distance (i.e., the distance traveled in the center of the arena) were recorded. The center distance was also divided by the total distance to obtain a center distance:total distance ratio. The center distance:total distance ratio has been used as an index of anxiety-related responses (Paylor et al. 2006). The number of fecal boli was recorded at the end of the experiment. Between each trial, the area was thoroughly cleaned with a 30\% isopropyl alcohol, then dried with paper towels. Data were collected in 2-min intervals over the 30-min test session and analyzed using independent-sample $t$-tests.

\section{Elevated plus maze}

Approximately 1 wk later, the elevated plus maze was used to evaluate whether the Kv4.2 KO mice had a baseline difference in anxiety. The elevated-plus maze apparatus consisted of two open and two enclosed horizontal perpendicular arms $(30 \times 5 \mathrm{~cm})$ positioned $40 \mathrm{~cm}$ above the floor. There also was a central square platform $(5 \times 5 \mathrm{~cm})$ that forms from the connection of the four arms. The mice were initially allowed to acclimate to the room for $30 \mathrm{~min}$. The experiments were conducted under artificial laboratory illumination (fluorescent lamps, 30 lux in the open arm) and a white noise generator that produced a $60-\mathrm{dB}$ background white noise. Between each trial, the maze was thoroughly cleaned with 30\% isopropyl alcohol and then dried with paper towels. The sessions were scored by an investigator blind to the genotype using a handheld Psion from Noldus Information Technology and later transferred to a computer with the Noldus Observer 5.0 program. During the 10-min test, the number of entries into the open or closed arms and the average time spent in each of the arms was recorded. The number of entries into open arms and the time spent in open arms were expressed as percentages of total entries and total test time, respectively. The increase in either measure is generally believed to be an index of lowered anxiety. The number of entries into closed arms is a rough index of animal activity.

\section{Morris water maze}

One week later, the Morris water maze (MWM) test was used to examine spatial learning deficits as previously described (McIlwain et al. 2001). The test used a $1.3-\mathrm{m}$ diameter circular pool, which was filled with water made opaque by the addition of a white nontoxic paint. The mouse movement was monitored by a video camera connected to a digital tracking device (Noldus: Ethovision). The mice were first allowed to acclimate to the room for $30 \mathrm{~min}$, then tested for their ability to locate a hidden square platform
$(14.5 \mathrm{~cm})$. The mice were tested for a total of $4 \mathrm{~d}$ (two blocks of trials per day with four trials per block) for their ability to locate a hidden platform that was located $\sim 1.5 \mathrm{~cm}$ beneath the surface of the water. Thirty minutes after the completion of the eighth block, each animal was given a probe trial. In the probe trial, the platform was removed and each animal was allowed $60 \mathrm{sec}$ to search the pool for the platform. The amount of time that each animal spent in each quadrant was recorded (quadrant time). The number of times a mouse crossed into the location where the hidden platform previously had been located was placed was recorded. These crossings were compared with the crossings in the other relative locations within the quadrant (zone crossing). The following day a visible platform test was conducted to evaluate whether the mice had difficulty in locating a visible platform. An inability or reduced ability to find the visible platform could be due to a visual or motor deficit.

\section{Prepulse inhibition}

Prepulse inhibition (PPI) testing was conducted 1-2 wk after MWM testing. PPI of acoustic startle responses was measured using the SR-Lab System (San Diego Instruments) as previously described (Paylor et al. 2006). A test session began by placing a mouse in a clear acrylic cylinder, where it was left undisturbed for $5 \mathrm{~min}$ with a constant background noise level of $70 \mathrm{~dB}$ throughout the entire testing period. There were seven trial types for a test session. One trial type was a $120-\mathrm{dB}$ sound burst $(40$ $\mathrm{msec}$ ) used as the startle stimulus. There were five different acoustic prepulse plus acoustic startle stimulus trials. The prepulse sound was presented $100 \mathrm{msec}$ before the startle stimulus. The 20 -msec prepulse sounds were $74,78,82,86$, or $90 \mathrm{~dB}$. In addition, there were trials where no stimuli were presented to the animal to measure baseline movement in the cylinders. Six blocks of the seven trial types were presented in pseudorandom order to ensure that each trial type was presented once within a block of seven trials. The average interval between trials was $15 \mathrm{sec}$ (ranged from 10 to $20 \mathrm{sec}$ ). The startle response was recorded for $65 \mathrm{msec}$ (the response was measured in $1-\mathrm{msec}$ increments) starting with the onset of the startle stimulus. The maximum startle amplitude recorded during the $65-\mathrm{msec}$ sampling window was used as the dependent variable.

The following formula previously described by Paylor et al. (2006) was used to calculate \% PPI of a startle response: 100 [(startle response on acoustic prepulse plus startle stimulus trials/startle response alone trials) $\times 100]$. A high \% PPI represents when the subject showed a reduced startle response to a prepulse stimulus compared with the startle stimulus alone. A low \% PPI value indicates where the startle response was similar to the one with or without the prepulse. Acoustic response amplitude data were analyzed using an independent-sample $t$-test. PPI data were analyzed using independent-sample $t$-tests for each PPI level.

\section{Pavlovian-conditioned fear}

Performance in a conditioned fear task was analyzed as previously described (Paylor et al. 1994; McIlwain et al. 2001) using the freeze monitor system (Actimetrics). The test chamber $(26 \times 22 \times$ $18 \mathrm{~cm}^{3}$ high) was made of clear Plexiglas and was placed inside a sound-attenuated chamber (Med Associates). Two sides of the box were Plexiglas, two sides were metal, and a grid floor bottom was used to deliver a mild foot shock. On the training day, mice were placed into the test chamber and allowed to explore for $2 \mathrm{~min}$. The conditioned stimulus (CS) was presented for $30 \mathrm{sec}$ (a white noise $80 \mathrm{~dB}$ sound) and was followed immediately by a mild foot shock ( $2 \mathrm{sec}, 0.7 \mathrm{~mA}$ ) that served as the unconditioned stimulus (US). After $2 \mathrm{~min}$, the mice received a second CS-US pairing. The FreezeFrame monitor system was used to control the timing of CS and US presentations. Freezing behavior was measured through the computer program. During the administration of the shock, responses to the foot shock such as running, jumping, or vocalizing were also recorded to verify that the animal received the shock. After each testing session the chamber was cleaned with $30 \%$ isopropyl alcohol. 
Mice were tested for contextual and cued fear conditioning $24 \mathrm{~h}$ after conditioning. For the context test, mice were placed back into the original test chamber for $5 \mathrm{~min}$ and their freezing behavior was recorded. Two hours later, mice were tested for responses to the auditory CS in a new environment. For the CS test, white Plexiglas inserts were placed on the sides and floor of the chamber to alter the shape, texture, and color of the conditioning chamber. The odor in the chamber was changed by adding vanilla extract to a cup located behind the wall insert. In addition, $70 \%$ ethanol was used to clean the chamber between test sessions. Transfer cages were altered (paper towels instead of bedding) and the lights were dimmed in the room with the conditioning chamber to change the entry context. Mice were placed into this new chamber and freezing was recorded for 3 min during this phase preceding the CS in this new context. The auditory CS was then presented for 3 min and freezing was recorded as described. Context and CS test data were analyzed using an independent-sample $t$-test.

\section{Western blotting}

Based on previous data showing that there is an increase in tonic inhibition in area CA1 in the hippocampus of $\mathrm{Kv} 4.2 \mathrm{KO}$ mice (Andrásfalvy et al. 2008), we evaluated protein levels in two $\mathrm{GABA}_{\mathrm{A}}$ subunits that could potentially be involved. Adult naive littermate mice (129S6/SvEvTaq and Kv4.2 knock-out mice) were decapitated, brains removed, and rapidly placed into ice-cold cutting saline (consisting of the following in millimolars: 110 sucrose, $3 \mathrm{KCl}, 60 \mathrm{NaCl}, 28 \mathrm{NaHCO}_{3}, 0.5 \mathrm{CaCl}_{2}, 5$ glucose, 0.6 ascorbate, $1.25 \mathrm{NaH}_{2} \mathrm{PO}_{4}$, and saturated with $95 \% \mathrm{O}_{2} / 5 \% \mathrm{CO}_{2}$ ). The hippocampi were removed, frozen on dry ice, and stored at $-80^{\circ} \mathrm{C}$ until use.

Total homogenate and crude synaptosomal preparations from samples were prepared using previously described methods (Lugo et al. 2008). Each sample was homogenized in ice-cold homogenization buffer $(0.32 \mathrm{M}$ sucrose, $10 \mathrm{mM}$ HEPES at $\mathrm{pH}$ 7.4), with a protease and phosphatase inhibitor cocktail (SigmaAldrich). Some of the sample was saved as total homogenate (input), and the remaining amount was used for crude synaptosomal preparations as previously described (Lugo et al. 2008). The protein concentration of each sample was determined using the Bio-Rad Protein assay (Bio-Rad laboratories, Inc.) and all samples were then normalized. SDS-Page (10\%) was performed and the gels were transferred to Immobolin-P membranes (Millipore).

For Western blotting, the membranes were blocked in 5\% dry milk dissolved in Tween-Tris buffered saline (TTBS; $50 \mathrm{mM}$ Tris at p.H, $150 \mathrm{mM} \mathrm{NaCl}, 0.1 \%$ Tween) for $1 \mathrm{~h}$ at room temperature. The membranes then were incubated with primary antibodies: 1:500 dilution of $\alpha 5 \mathrm{GABA}_{\mathrm{A}} \mathrm{R}$ or $\delta \mathrm{GABA}_{\mathrm{A}} \mathrm{R}$ antibody (Abcam) and a 1:5000 dilution of actin antibody (Sigma-Aldrich) overnight, followed by incubation with a 1:10000 anti-rabbit secondary antibody in TTBS (Cell Signaling). Immunoreactive bands were then visualized by enhanced chemiluminescence (Thermo Scientific). Immunoreactivity was quantified using NIH Image J public domain software. The band for each sample was normalized to its actin level.

\section{Pharmacological inhibition of tonic inhibition studies}

In order to further examine whether a compensatory increase in tonic inhibition was responsible for the learning and memory differences in the MWM test, we administered the $\mathrm{GABA}_{\mathrm{A}} \mathrm{R}$ antagonist, picrotoxin as previously described (Cui et al. 2008). This dose was expected to suppress tonic inhibition, but was subthreshold for the induction of seizures. The mice were injected (IP) with $0.01 \mathrm{mg} / \mathrm{Kg}$ with picrotoxin (Tocris) or saline (vehicle) $3 \mathrm{~d}$ prior to MWM testing. They then were injected with picrotoxin or saline $30 \mathrm{~min}$ prior to MWM testing every day.

\section{Statistical analysis}

All statistical testing was conducted using the SPSS 17.0 software package (SPSS, Inc.). Differences were considered statistically sig- nificant at the two-tailed $P<0.05$ level for all tests. For the MWM, the escape latency data were analyzed with a mixed-design ANOVA. Subsequent independent-sample $t$-tests were conducted if an interaction between genotype and block was found. Differences in quadrant time and number were analyzed by repeatedmeasures ANOVA, and individual differences between groups within each quadrant were analyzed using independent-sample $t$-tests. The escape latency for the visible platform testing was recorded for four trials averaged within each subject and was then analyzed across genotype through an independent-sample $t$-test. For the other behavioral tests and Western blotting the data were analyzed using Student's $t$-tests.

\section{Acknowledgments}

This research was funded by the Epilepsy Foundation and NIH NS056664 Postdoctoral Fellowships to J.N.L., an Epilepsy Foundation and NIH NS43124 Postdoctoral Fellowships to A.L.B., and NIH NINDS grants NS049427 and NS039943 to A.E.A. The work was completed in the Baylor College of Medicine Intellectual and Developmental Disabilities Research Center (IDDRC) Mouse Neurobehavior Core, which receives funding from the NIH P30HD 024064 from the Eunice Kennedy Shriver Institute of Child Health \& Human Development. The content is solely the responsibility of the authors and does not necessarily represent the official views of the Eunice Kennedy Shriver National Institute of Child Health \& Human Development or the NIH.

\section{References}

Alexander JC, McDermott CM, Tunur T, Rands V, Stelly C, Karhson D, Bowlby MR, An WF, Sweatt JD, Schrader LA. 2009. The role of calsenilin/DREAM/KChIP3 in contextual fear conditioning. Learn Mem 16: $167-177$.

Andrásfalvy BK, Makara JK, Johnston D, Magee JC. 2008. Altered synaptic and non-synaptic properties of CA1 pyramidal neurons in Kv4.2 knockout mice. J Physiol 586: 3881-3892.

Baldwin TJ, Tsaur M-L, Lopez GA, Jan YN, Jan LY. 1991. Characterization of a mammalian cDNA for an inactivating voltage-sensitive $\mathrm{K}^{+}$channel. Neuron 7: 471-483.

Barnwell LF, Lugo JN, Lee WL, Willis SE, Gertz SJ, Hrachovy RA, Anderson AE. 2009. Kv4.2 knockout mice demonstrate increased susceptibility to convulsant stimulation. Epilepsia 50: 1741-1751.

Bernard C, Anderson A, Becker A, Poolos NP, Beck H, Johnston D. 2004 Acquired dendritic channelopathy in temporal lobe epilepsy. Science 305: $532-535$.

Birnbaum SG, Varga AW, Yuan LL, Anderson AE, Sweatt JD, Schrader LA. 2004. Structure and function of Kv4-family transient potassium channels. Physiol Rev 84: 803-833.

Cai X, Liang CW, Muralidharan S, Kao JP, Tang CM, Thompson SM. 2004 Unique roles of SK and Kv4.2 potassium channels in dendritic integration. Neuron 44: 351-364.

Caraiscos VB, Elliott EM, You-Ten KE, Cheng VY, Belelli D, Newell JG, Jackson MF, Lambert JJ, Rosahl TW, Wafford KA, et al. 2004. Tonic inhibition in mouse hippocampal CA1 pyramidal neurons is mediated by $\alpha 5$ subunit-containing $\gamma$-aminobutyric acid type A receptors. Proc Natl Acad Sci 101: 3662-3667.

Chen X, Yuan LL, Zhao C, Birnbaum SG, Frick A, Jung WE, Schwarz TL, Sweatt JD, Johnston D. 2006. Deletion of Kv4.2 gene eliminates dendritic A-type $\mathrm{K}^{+}$current and enhances induction of long-term potentiation in hippocampal CA1 pyramidal neurons. J Neurosci 26: 12143-12151.

Collinson N, Kuenzi FM, Jarolimek W, Maubach KA, Cothliff R, Sur C, Smith A, Otu FM, Howell O, Atack JR, et al. 2002. Enhanced learning and memory and altered GABAergic synaptic transmission in mice lacking the $\alpha 5$ subunit of the GABAA receptor. J Neurosci 22: $5572-5580$

Cui Y, Costa RM, Murphy GG, Elgersma Y, Zhu Y, Gutmann DH, Parada LF, Mody I, Silva AJ. 2008. Neurofibromin regulation of ERK signaling modulates GABA release and learning. Cell 135: 549-560.

Glykys J, Mann EO, Mody I. 2008. Which GABA(A) receptor subunits are necessary for tonic inhibition in the hippocampus? J Neurosci 28: $1421-1426$.

Guo W, Jung WE, Marionneau C, Aimond F, Xu H, Yamada KA, Schwarz TL, Demolombe S, Nerbonne JM. 2005. Targeted deletion of Kv4.2 eliminates $\mathrm{I}(\mathrm{to}, \mathrm{f})$ and results in electrical and molecular remodeling, with no evidence of ventricular hypertrophy or myocardial dysfunction. Circ Res 97: 1342-1350. 
Hoffman DA, Magee JC, Colbert CM, Johnston D. 1997. $\mathrm{K}^{+}$channel regulation of signal propagation in dendrites of hippocampal pyramidal neurons. Nature 387: 869-875.

Johnston D, Hoffman DA, Magee JC, Poolos NP, Watanabe S, Colbert CM, Migliore M. 2000. Dendritic potassium channels in hippocampal pyramidal neurons. J Physiol 1: 75-81.

Jung S-C, Kim J, Hoffman DA. 2008. Rapid, bidirectional remodeling of synaptic NMDA receptor subunit composition by A-type $\mathrm{K}^{+}$channel activity in hippocampal CA1 pyramidal neurons. Neuron 60: 657-671.

Kim J, Jung SC, Clemens AM, Petralia RS, Hoffman DA. 2007. Regulation of dendritic excitability by activity-dependent trafficking of the A-type $\mathrm{K}^{+}$ channel subunit Kv4.2 in hippocampal neurons. Neuron 54: 933-947.

Koh SD, Ward SM, Dick GM, Epperson A, Bonner HP, Sanders KM, Horowitz B, Kenyon JL. 1999. Contribution of delayed rectifier potassium currents to the electrical activity of murine colonic smooth muscle. J Physiol 515: 475-487.

Lockridge A, Yuan LL. 2010. Spatial learning deficits in mice lacking A-type $\mathrm{K}^{+}$channel subunits. Hippocampus 21: 1152-1156.

Lugo JN, Barnwell LF, Ren Y, Lee WL, Johnston LD, Kim R, Hrachovy RA, Sweatt JD, Anderson AE. 2008. Altered phosphorylation and localization of the A-type channel, Kv4.2 in status epilepticus. J Neurochem 106: 1929-1940.

Malenka RC, Bear MF. 2004. LTP and LTD: An embarrassment of riches. Neuron 44: 5-21.

Maletic-Savatic M, Lenn NJ, Trimmer JS. 1995. Differential spatiotemporal expression of $\mathrm{K}^{+}$channel polypeptides in rat hippocampal neurons developing in situ and in vitro. J Neurosci 15: 3840-3851.

Martina M, Schultz JH, Ehmke H, Monyer H, Jonas P. 1998. Functional and molecular differences between voltage-gated $\mathrm{K}^{+}$channels of fast-spiking interneurons and pyramidal neurons of rat hippocampus. J Neurosci 18: 8111-8125.

McIlwain KL, Merriweather MY, Yuva-Paylor LA, Paylor R. 2001. The use of behavioral test batteries: Effects of training history. Physiol Behav 73: $705-717$.

Menegola M, Trimmer JS. 2006. Unanticipated region- and cell-specific downregulation of individual KChIP auxiliary subunit isotypes in Kv4.2 knock-out mouse brain. J Neurosci 26: 12137-12142.
Migaud M, Charlesworth P, Dempster M, Webster LC, Watabe AM, Makhinson M, He Y, Ramsay MF, Morris RG, Morrison JH, et al. 1998. Enhanced long-term potentiation and impaired learning in mice with mutant postsynaptic density-95 protein. Nature 396: 433-439.

Paylor R, Tracy R, Wehner J, Rudy JW. 1994. DBA/2 and C57BL/6 mice differ in contextual fear but not auditory fear conditioning. Behav Neurosci 108: 810-817.

Paylor R, Spencer CM, Yuva-Paylor LA, Pieke-Dahl S. 2006. The use of behavioral test batteries, II: Effect of test interval. Physiol Behav 87: 95-102.

Rhodes KJ, Carroll KI, Sung MA, Doliveira LC, Monaghan MM, Burke SL, Strassle BW, Buchwalder L, Menegola M, Cao J, et al. 2004. KChIPs and $\mathrm{Kv} 4 \alpha$ subunits as integral components of A-type potassium channels in mammalian brain. J Neurosci 24: 7903-7915.

Sanes JR, Lichtman JW. 1999. Can molecules explain long-term potentiation? Nat Neurosci 2: 597-604.

Serodio P, Rudy B. 1998. Differential expression of $\mathrm{Kv} 4 \mathrm{~K}^{+}$channel subunits mediating subthreshold transient $\mathrm{K}^{+}$(A-type) currents in rat brain. $J$ Neurophysiol 79: 1081-1091.

Sheng M, Tsaur M-L, Jan YN, Jan LY. 1992. Subcellular segregation of two A-type $\mathrm{K}^{+}$channel proteins in rat central neurons. Neuron 9: 271-284.

Singh B, Ogiwara I, Kaneda M, Tokonami N, Mazaki E, Baba K, Matsuda K, Inoue Y, Yamakawa K. 2006. A Kv4.2 truncation mutation in a patient with temporal lobe epilepsy. Neurobiol Dis 24: 245-253.

Wiltgen BJ, Sanders MJ, Ferguson C, Homanics GE, Fanselow MS. 2005. Trace fear conditioning is enhanced in mice lacking the $\delta$ subunit of the GABAA receptor. Learn Mem 12: 327-333.

Yuan LL, Chen X. 2006. Diversity of potassium channels in neuronal dendrites. Prog Neurobiol 78: 374-389.

Zamanillo D, Sprengel R, Hvalby O, Jensen V, Burnashev N, Rozov A, Kaiser KM, Koster HJ, Borchardt T, Worley P, et al. 1999. Importance of AMPA receptors for hippocampal synaptic plasticity but not for spatial learning. Science 284: $1805-1811$.

Received July 19, 2011; accepted in revised form February 22, 2012. 


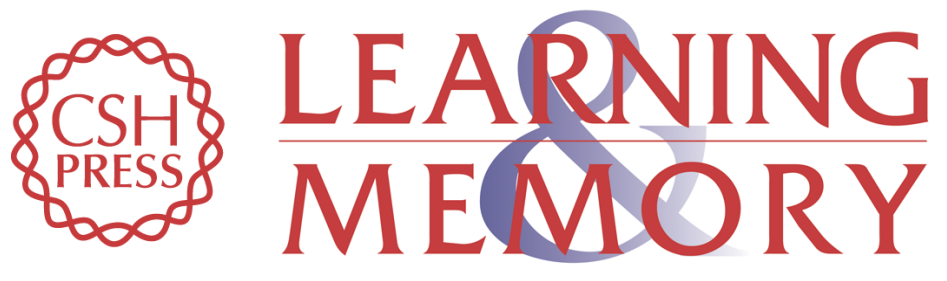

\section{Kv4.2 knockout mice have hippocampal-dependent learning and memory deficits}

Joaquin N. Lugo, Amy L. Brewster, Corinne M. Spencer, et al.

Learn. Mem. 2012, 19:

Access the most recent version at doi:10.1101//m.023614.111

References This article cites 36 articles, 13 of which can be accessed free at:

http://learnmem.cshlp.org/content/19/5/182.full.html\#ref-list-1

License

Email Alerting Receive free email alerts when new articles cite this article - sign up in the box at the Service top right corner of the article or click here. 